\title{
Vertical Profiling and Contamination Risk Assessment of Some Trace Metals in Lagos Lagoon Axis
}

\author{
Popoola Samuel Olatunde, Nubi Olubunmi Ayoola, Oyatola Opeyemi Otolorin, \\ Adekunbi Falilu Olaiwola, Fabunmi Gaffar Idera, Nwoko Chidinma Jecinta \\ Department of Physical and Chemical Oceanography, Nigerian Institute for Oceanography and Marine Research, Lagos, Nigeria
}

Email address:

popoolaos@niomr.gov.ng (P. S. Olatunde)

\section{To cite this article:}

Popoola Samuel Olatunde, Nubi Olubunmi Ayoola, Oyatola Opeyemi Otolorin, Adekunbi Falilu Olaiwola, Fabunmi Gaffar Idera,„Nwoko Chidinma Jecinta. Vertical Profiling and Contamination Risk Assessment of Some Trace Metals in Lagos Lagoon Axis. International Journal of Science, Technology and Society. Vol. 3, No. 4, 2015, pp. 156-163. doi: 10.11648/j.ijsts.20150304.19

\begin{abstract}
Lagos Harbour (a Lagos lagoon axis) serves as a route for goods transportation, coupled with proliferation of urban and industrial establishments. The socioeconomic activities within has often led to the introduction of substantial wastes, marine debris and spills into the harbor. In an attempt to monitor the pollution status of aquatic organisms in the Lagos Lagoon axis, vertical profiling of the trace metal contents was carried out to reveal, the vertical variations in the monthly trends of; $\mathrm{Cu}$, $\mathrm{Zn}, \mathrm{Pb}, \mathrm{Cr}, \mathrm{Mn}, \mathrm{Ni}$, and Fe between August and October,2014.Chemical analysis was carried out in the Nigerian institute for oceanography and marine research (NIOMR) wet and instrumentation laboratory, using aqua regia digestion methods and 200AA series Atomic Absorption Spectrophotometer. The observed levels of the trace metals shows a decreasing order of abundance; $\mathrm{Fe}>\mathrm{Cr}>\mathrm{Pb}>\mathrm{Mn}>\mathrm{Ni}>\mathrm{Zn}>\mathrm{Cu}$; $\mathrm{Fe}>\mathrm{Pb}>\mathrm{Cr}>\mathrm{Ni}>\mathrm{Mn}>\mathrm{Zn}>\mathrm{Cu}$ and $\mathrm{Fe}>\mathrm{Cr}>\mathrm{Pb}>\mathrm{Ni}>\mathrm{Mn}>\mathrm{Zn}>\mathrm{Cu}$ for 0.2 meters, 2.6 meters and 5.2meters respective depth profile. This study reveal a general contamination trends; medium depth $(2.6 \mathrm{~m})>$ bottom depth $(5.2 \mathrm{~m})>$ surface depth $(0.2 \mathrm{~m})$. Higher metal concentrations were observed in October. All observed trace metals except $\mathrm{Cu}, \mathrm{Zn}$ and $\mathrm{Fe}$ exhibit high contamination ratio. The trace metals distributions in the study area are majorly controlled by; precipitations, dilution, anthropogenic activities and Sea/fresh water incursion from the Atlantic Ocean and the adjourning creeks. A strong regulation in the indiscriminate waste dump and a check in the socioeconomic activities in the Lagos Harbour are very essential.
\end{abstract}

Keywords: Lagos Harbour, Marine Debris, Atomic Absorption Spectrophotometer, Trace Metals, Contamination Ratio, Anthropogenic Activities

\section{Introduction}

Trace metals such as chromium, cobalt, copper, iron, nickel, manganese, lead, copper and zinc, are elements that normally occur at very low levels $(<1000 \mathrm{ppm})$ in the environment (Dara and Rashmi, 2009). Living things are in need of a very small amount of these trace metals, as high concentrations can become toxic. They are present in seawater in trace concentrations, whereas excessive concentration can affect marine biota, pose risk to consumers of sea food and change the physical and chemical characteristics of the water [1]

Pollution cases such as sewage sludge, wood burning / log transportation, feacal disposals, oil tankers transportations, landfill site, vehicular emissions, sand dredging, and agricultural effluents have been reported in the Lagos lagoon
$[2,3,4]$. The continuous growth in human population and materials consumed in Lagos have led to the generation of substantial wastes of unprecedented quantities which are no more mere nuisance, but toxic and hazardous to the environment [5].

Although Lagos harbor (an extension of the Lagos lagoon axis) figure 1, serves as a seaport and centre for recreational sailing, it has also been regarded as a sink for domestic and industrial wastes [6]. However, there is paucity of information on the extent of pollution resulting from coastal activities such as marine debris deposition, oil contamination, ships/commercial boating spills, naval vessel discharges, dredging, sitting and construction of socio-economical activities within the Lagos harbor[7-10]; hence it becomes imperative to continually monitor the pollution status of the Lagos Lagoon axis. This paper therefore aims at assessing 
the vertical variations in the concentration of some trace metals: $\mathrm{Pb}, \mathrm{Mn}, \mathrm{Zn}, \mathrm{Cr}, \mathrm{Fe}, \mathrm{Ni}$ and $\mathrm{Cu}$ in the study area and also seeks to examine their sources and environmental consequences.

\section{Description of the Study Area}

Lagos is situated in south-western Nigeria on the West Coast of Africa and is undoubtedly the commercial nervecenter of Nigeria. Geologically; it falls within the eastern part of the Dahomey Basin, bounded to the north by then Precambrian Basement complex of southwestern Nigeria. It is bounded by the Gulf of Guinea to the south and eastward by the Okitipupa ridge [11]. The harbour (figure 1) situated in Lagos is Nigeria's most important seaport and the first inlet from the Atlantic Ocean, beyond the Republic of Benin[12]. It is one of the three main segments of Lagos Lagoon Complex; other segments are: Metropolitan and the Epe Division Segments. It is $2 \mathrm{~km}$ wide and receives inland waters from the Lagos Lagoon in the north, and from Badagry Creek in the west. Oil depots are located along the shore of western parts coupled with the proliferation of urban and industrial establishments on the shore of eastern part. NIOMR jetty station (Latitude $6^{\circ} 25^{\prime} 14,88^{\circ} \mathrm{N}$, Longitude $3^{\circ}$ $24^{\prime} 24,42^{\circ} \mathrm{E}$ ) is located in the commodore channel of Lagos harbour with Jetty facilities awaiting rehabilitation. Subsistence fishing takes place at this part on the water body by artisanal fishermen [13].

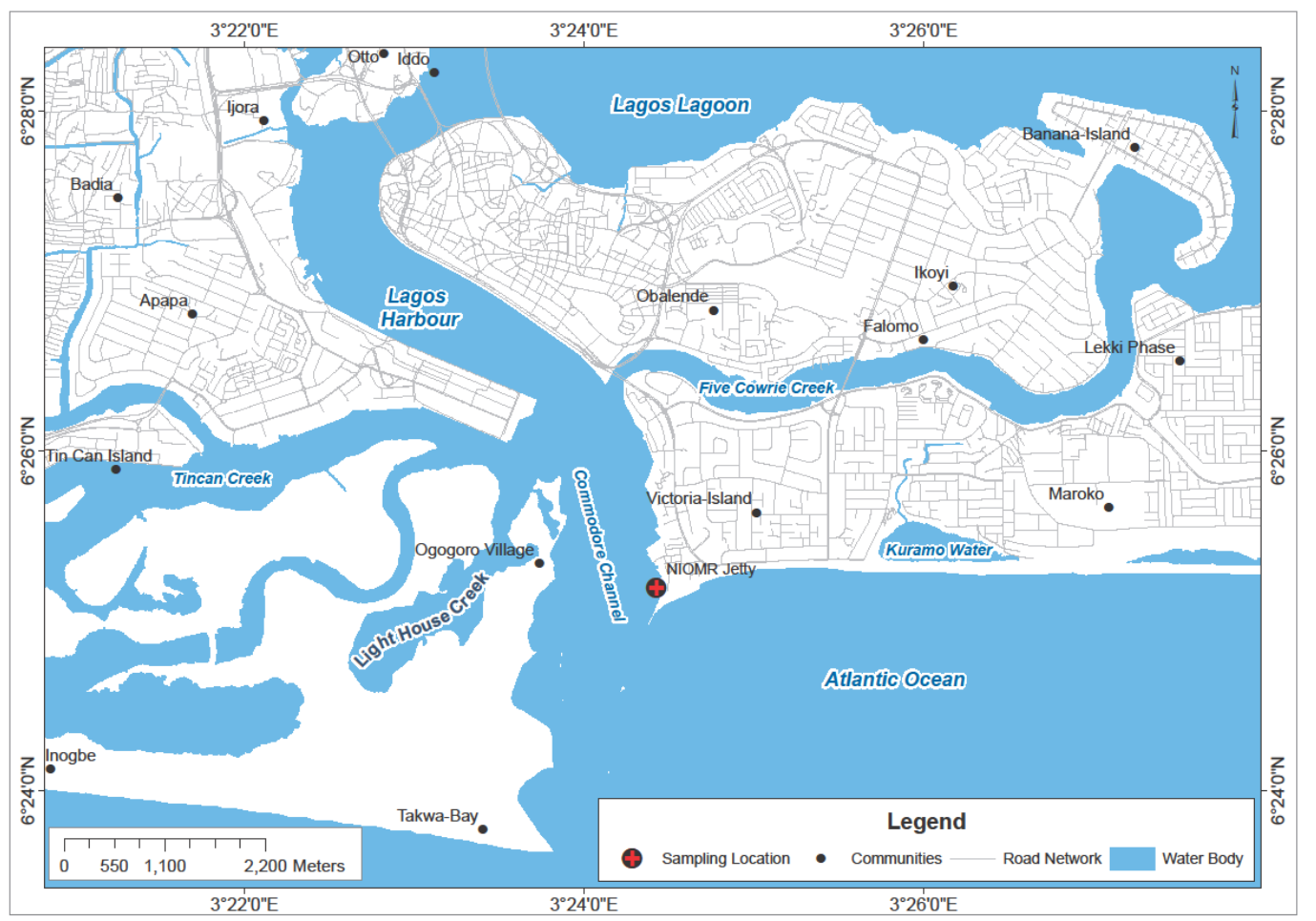

Fig. 1. Map of Lagos Harbor showing the NIOMR Jetty platform.

\section{Material and Methods}

Surface water samples from the Nigerian Institute for Oceanography and Marine Research Jetty, henceforth termed NIOMR Jetty were collected with the aid of $500 \mathrm{ml}$ container at about $0.2 \mathrm{~m}$ depth. Water samples at 2.6 meters and 5.2 meters depth were collected with the aids of $1 \mathrm{dm}^{3}$, 0.1 meters diameter water sampler attached to a graduated rope of 10meters long. Samples were collected from August to October 2014.The samples were acidified with 2 to $3 \mathrm{ml}$ of nitric acid $\left(\mathrm{HNO}_{3}\right)$ in pre-cleaned 1 litre plastic containers at the sampling point so as to ensure that the respective ions remain in solution pending analysis. Trace metal contents $(\mathrm{Pb}$, $\mathrm{Cr}, \mathrm{Cu}, \mathrm{Ni}, \mathrm{Fe}, \mathrm{Mn}$ and $\mathrm{Zn}$ ) in the respective depth profiled were analysed with argillent 200 A model, Atomic Absorption Spectrophotometer (AAS), after the samples had been digested with Nitric/Hydrochloric acid (1:3), aqua regia using standard digestion procedure [14]. The results obtained from the analysis were subjected to various contamination ratios and standards to ascertain the metal's natural or anthropogenic enrichment in the NIOMR Jetty water body.

The sampling point was inaccessible at a certain time (late August and mid September) during the sampling period due to high precipitation and tidal fluctuations.

\section{Statistical Analysis}

All descriptive statistics and graphs were executed using Statistical 7 software and Microsoft office Excel 2010. Data were further subjected to Correlation test to find significant relationship between the measured variables at 0.05 levels of significance 


\section{Results}

The mean concentrations of some trace metals in water samples are shown in figure 2. Chromium has the highest value $(7.06 \pm 0.81 \mathrm{mg} / \mathrm{l})$ at depth 5.2 meters in October and least value $(3.21 \pm 0.69 \mathrm{mg} / \mathrm{l})$ in August at $2.6 \mathrm{~meters}$ depth. The peak concentration for Lead $(6.98 \pm 0.59 \mathrm{mg} / \mathrm{l})$ is at 2.6 meters depth and the least value $(0.04 \pm 0.01 \mathrm{mg} / \mathrm{l})$ was at 0.2 meters in October. Iron exhibits the highest values (14.88 $\pm 5.6 \mathrm{mg} / \mathrm{l})$ in October at depth 5.2meters and lowest concentration $(3.09 \pm 0.58 \mathrm{mg} / \mathrm{l})$ at 2.6 meters in August. The highest concentration for $\mathrm{Mn}(2.59 \pm 0.37 \mathrm{mg} / \mathrm{l})$ and $\mathrm{Ni}(1.57$ $\pm 0.03 \mathrm{mg} / \mathrm{l})$ were recorded in October and September at 0.2 meters and 5.2meters while, the lowest values $0.09 \pm$ $0.02 \mathrm{mg} / 1$ and $0.47 \pm 0.08 \mathrm{mg} / 1$ were recorded in August and October at 0.2 meters respectively. Copper and Zinc have lowest concentration in all the water samples however, it has peak values of $0.43 \pm 0.02 \mathrm{mg} / 1$ at 2.6 meters and $1.04 \pm$ $0.07 \mathrm{mg} / 1$ in August at 2.6 meters and their respective lowest values of $0.03 \pm 0.02 \mathrm{mg} / 1$ and $0.12 \pm 0.06 \mathrm{mg} / 1$ in October and August at 5.2meters.

\section{Contamination Ratios}

Other contamination ratios such as-: contamination factor, contamination degree and pollution load index were applied to evaluate the contamination status of the Lagos Harbour at the NIOMR Jetty sampling points (see table $3 \& 4$ ). The contamination factor was used in this study to evaluate the degree of trace metal contamination in water samples [15, 16]. The permissible levels, the element co ncentration in the water considered safe for marine organisms [17, 18.] were used as background level for the contamination factor, contamination degree and the pollution index ratio. Contamination factor, $\mathrm{Cf}=\mathrm{C} / \mathrm{Cn}$, where, $\mathrm{Cf}=$ contamination factor; $\mathrm{C}=$ mean concentration of each metal in water sample; $\mathrm{Cn}=$ permissible level of trace metal concentration in water (table 5\&6).Contamination degree (DC) is the sum of the contamination factors of all the elements examined, degrees of contamination were calculated using the formulae-:mDC $=\Sigma \mathrm{Cf}[17]$, Where $\Sigma$ is the summation of the contamination factors examined.

The Pollution load index (PLI) is a result of the contribution of several trace metals and it is defined as the root of the ratio of concentration factor to the number of heavy metal. PI $=$ Root $\sum$ (Heavy metal concentration in water/ (Tolerable level)/Number of Heavy metals [18, 19].Values of PLI $=1$ indicate heavy metal loads close to background, and values above 1 indicate progressive pollution [20].

\section{Correlation Matrix}

Correlation Matrix was employed for the data set to discover similarities in geochemical behaviour and basic relationship among the trace metals [21]. Correlation coefficient measures the strength of a linear relationship between two variables on a scale of -1 (perfect inverse relationship) through 0 (no relation) to +1 (perfect sympathetic relation). The correlation coefficients developed for trace metals in the study area was based on 21 samples (7 samples each of 0.2 meters, 2.6meters and 5.2meters depth) and it's significant from 0.5 at 0.05 confidence level see table 4.

Various ranges of ' $r$ ' were observed between the trace metals. The correlation that exists among the trace metals contents of the study area can be summarised as follows; All trace metals are non significantly correlated $(\mathrm{P}>0.05)$. $\mathrm{Cr}$ exhibits a negative correlation with other trace metals; $\mathrm{Mn}$ is positively correlated with $\mathrm{Zn}$, and negative correlated with $\mathrm{Cr}$ and $\mathrm{Fe} . \mathrm{Pb}$ is strongly correlated with $\mathrm{Cu}$ and $\mathrm{Ni}$ while, $\mathrm{Cu}$ correlated strongly with Fe.

Scattered plots were plotted for those metals showing some reasonable level of correlations and (see fig 3-5).

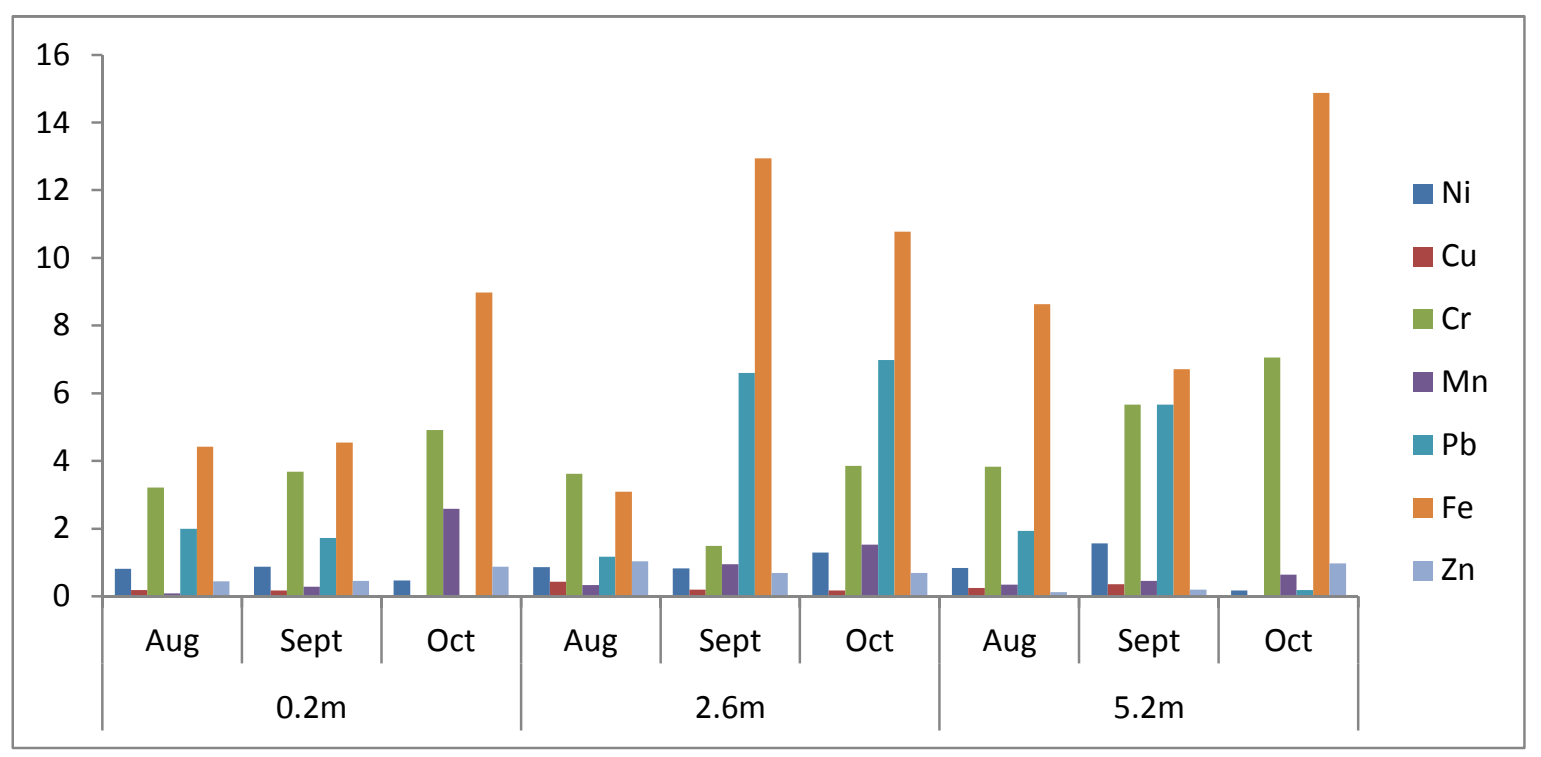

Fig. 2. Showing the monthly concentration of the trace metals (mg/l) sample. 
Table 1. Mean values \pm SD of Major/trace metal concentration in the study area.

\begin{tabular}{|c|c|c|c|c|c|c|c|}
\hline & & & 0.2meters & & & & \\
\hline Months & $\mathrm{Ni}(\mathrm{mg} / \mathrm{l})$ & $\mathrm{Cu}(\mathrm{mg} / \mathrm{l})$ & $\mathrm{Cr}(\mathrm{mg} / \mathrm{l})$ & $\mathrm{Mn}(\mathrm{mg} / \mathrm{l})$ & $\mathrm{Pb}(\mathrm{mg} / \mathrm{l})$ & $\mathrm{Fe}(\mathrm{mg} / \mathrm{l})$ & $\mathrm{Zn}(\mathrm{mg} / \mathrm{l})$ \\
\hline Aug,2014 & $0.82 \pm 0.09$ & $0.19 \pm 0.10$ & $3.21 \pm 0.69$ & $0.09 \pm 0.07$ & $2.00 \pm 0.35$ & $4.42 \pm 1.07$ & $0.45 \pm 0.36$ \\
\hline Sept,2014 & $0.88 \pm 0.29$ & $0.17 \pm 0.01$ & $3.68 \pm 0.37$ & $0.29 \pm 0.131$ & $1.73 \pm 0.39$ & $4.54 \pm 0.90$ & $0.46 \pm 0.45$ \\
\hline Oct,2014 & $0.47 \pm 0.28$ & ND & $\begin{array}{l}4.92 \pm 0.42 \\
2.6 \text { meters }\end{array}$ & $2.59 \pm 0.37$ & $0.04 \pm 0.01$ & $8.98 \pm 2.59$ & $0.88 \pm 0.16$ \\
\hline Aug,2014 & $0.86 \pm 0.12$ & $0.43 \pm 0.02$ & $3.62 \pm 0.05$ & $0.33 \pm 0.08$ & $1.17 \pm 0.62$ & $3.09 \pm 0.58$ & $1.04 \pm 0.37$ \\
\hline Sept,2014 & $0.83 \pm 0.2$ & $0.20 \pm 0.1$ & $1.49 \pm 0.4$ & $0.95 \pm 0.3$ & $6.60 \pm 2.2$ & $12.94 \pm 3.52$ & $0.69 \pm 0.15$ \\
\hline Oct,2014 & $1.29 \pm 0.83$ & $0.17 \pm 0.1$ & $\begin{array}{l}3.86 \pm 1.50 \\
5.2 \text { meters }\end{array}$ & $1.53 \pm 0.05$ & $6.98 \pm 0.59$ & $10.78 \pm 1.94$ & $0.69 \pm 0.39$ \\
\hline Aug,2014 & $0.84 \pm 0.06$ & $0.25 \pm 0.04$ & $3.83 \pm 0.41$ & $0.35 \pm 0.009$ & $1.94 \pm 0.39$ & $8.63 \pm 3.16$ & $0.12 \pm 0.06$ \\
\hline Sept,2014 & $1.57 \pm 0.88$ & $0.36 \pm 0.20$ & $5.67 \pm 1.51$ & $0.46 \pm 0.25$ & $5.67 \pm 1.51$ & $6.71 \pm 2.55$ & $0.20 \pm 0.1$ \\
\hline Oct,2014 & $0.18 \pm 0.09$ & $0.03 \pm 0.02$ & $7.06 \pm 0.81$ & $0.64 \pm 0.22$ & $0.19 \pm 0.27$ & $14.88 \pm 5.62$ & $0.97 \pm 1.05$ \\
\hline
\end{tabular}

ND: Not detected

Table 2. Contamination factor/degree and pollution index of trace metals with depth.

\begin{tabular}{|c|c|c|c|c|}
\hline Trace metal & CF(0.2Meters) & CF(2.6Meters) & CF(5.2Meters) & Background limit \\
\hline $\mathrm{Ni}$ & 18.00 & 24.75 & 21.50 & 0.04 \\
\hline $\mathrm{Cu}$ & 0.06 & 0.14 & 0.11 & 2.00 \\
\hline $\mathrm{Cr}$ & 39.4 & 29.9 & 55.20 & 0.10 \\
\hline $\mathrm{Mn}$ & 24.75 & 23.50 & 12.00 & 0.04 \\
\hline $\mathrm{Pb}$ & 12.60 & 49.60 & 26.00 & 0.10 \\
\hline $\mathrm{Fe}$ & 0.10 & 0.06 & 0.05 & 0.60 \\
\hline $\mathrm{Zn}$ & 0.12 & 0.16 & 0.09 & 5.00 \\
\hline DC & 94.93 & 128.05 & 114.90 & \\
\hline PLI & 4.88 & 5.64 & 5.35 & \\
\hline
\end{tabular}

Cf-contamination factor, DC-degree of contamination, PLI-pollution load index, Background limit (mg/l).

Table 3. Standard ratio of contamination factor /degree, Hakanson (1980).

\begin{tabular}{llll}
\hline Contamination factor & & Contamination degree(C deg) & Indication \\
\hline Class & Indication & Class & low degree of contamination \\
$\mathrm{Cf}<1$ & Low contamination & $\mathrm{DC}<8$ & Moderate degree of contamination \\
$1<\mathrm{Cf}<3$ & Moderate contamination factor & $8 \leq \mathrm{DC}<16$ & Considerable degree of contamination \\
$3<\mathrm{Cf}<6$ & Considerable contamination factor & $16 \leq \mathrm{DC}<32$ & Very high degree of contamination \\
$6<\mathrm{Cf}$ & Very high contamination & $32 \leq \mathrm{DCdeg}$ & \\
\hline
\end{tabular}

Cf-contamination factor, DC-degree of contamination

Table 4. Correllation coefficient matrix of analysed trace metals.

\begin{tabular}{|c|c|c|c|c|c|c|c|}
\hline & $\mathrm{Cr}$ & Mn & $\mathbf{P b}$ & $\mathrm{Cu}$ & $\mathbf{N i}$ & $\mathrm{Zn}$ & $\mathrm{Fe}$ \\
\hline $\mathrm{Cr}$ & 1.00 & & & & & - & \\
\hline $\mathrm{Mn}$ & -0.89 & 1.00 & & & & & \\
\hline $\mathrm{Pb}$ & -0.51 & 0.06 & 1.00 & & & & \\
\hline $\mathrm{Cu}$ & -0.22 & -0.25 & 0.95 & 1.00 & & & \\
\hline $\mathrm{Ni}$ & -0.35 & -0.11 & 0.98 & 0.99 & 1.00 & & \\
\hline $\mathrm{Zn}$ & -0.98 & 0.77 & 0.69 & 0.42 & 0.55 & 1.00 & \\
\hline $\mathrm{Fe}$ & 0.40 & -0.77 & 0.58 & 0.81 & 0.71 & -0.19 & 1.00 \\
\hline
\end{tabular}

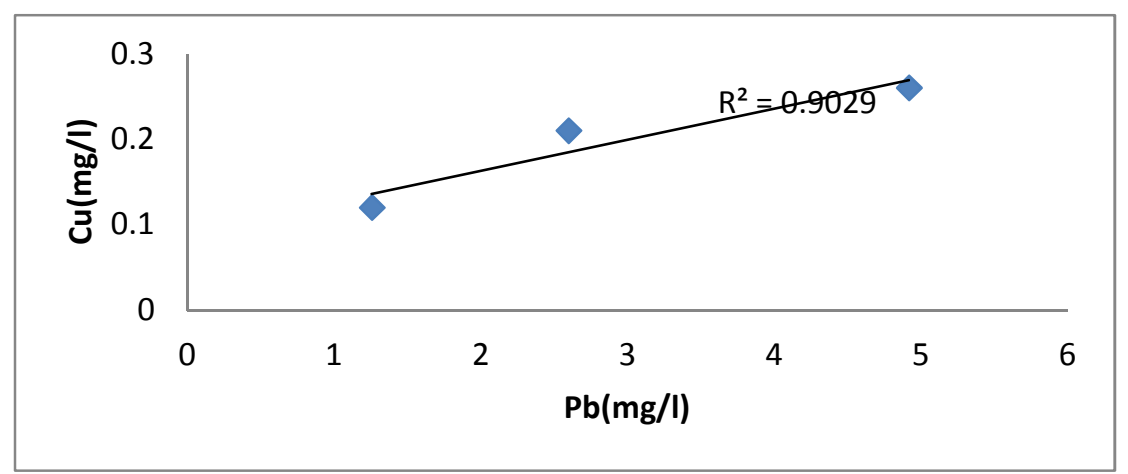

Fig. 3. Plot of $\mathrm{Cu}$ against $\mathrm{Pb}$ concentration. 


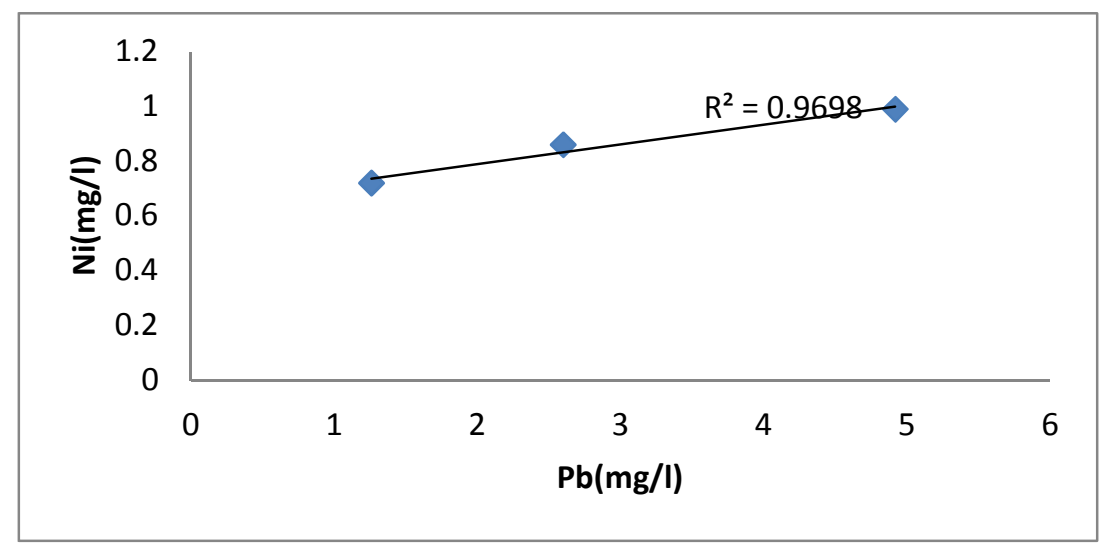

Fig. 4. Plot of Ni against Pb concentration.

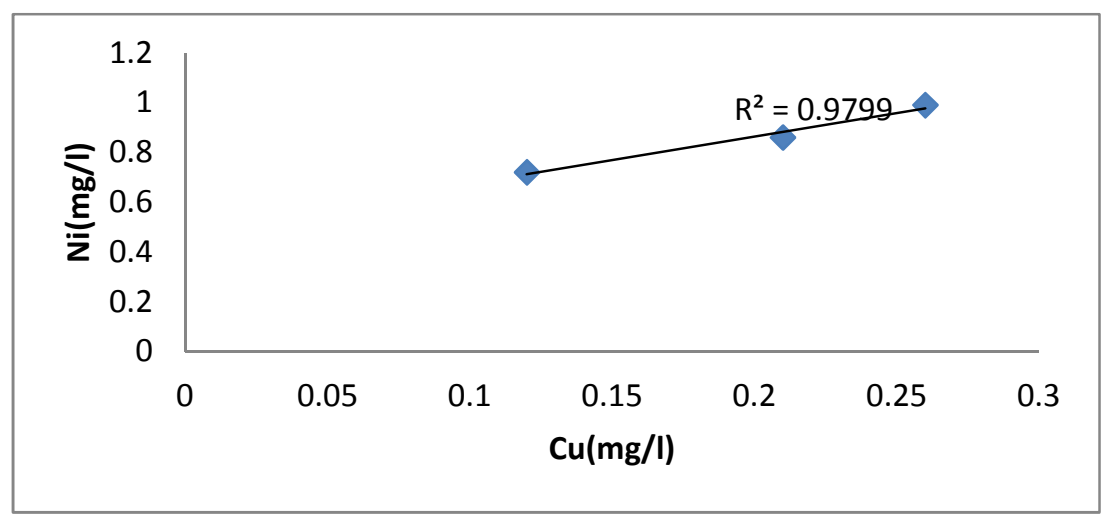

Fig. 5. Plot of Ni against Cu concentration.

\section{Discussions}

The contamination factor $(\mathrm{CF})$ for Copper $(\mathrm{Cu})$ and zinc $\mathrm{Zn})$ for the surface, medium and bottom depth profile (0.2meters, 2.6meters and 5.2meters) at the NIOMR Jetty are: $0.06,0.140 .11$ and the latter $0.12,0.16$ and 0.09 respectively. These values are less than $1(\mathrm{CF}<1)$, hence exhibit low degree of contamination (see table2\&3). However, Lead (12.0, 49.6, 26.0), Chromium (39.4, 29.9, 55.2), Manganese (24.75, $23.50,12.00)$ and Nickel $(\mathrm{Ni}, 18.00,24.75$, and 21.50) at 0.2 meters, 2.6 meters and 5.6 meters respectively all fall above a highly contaminated index ratio, $\mathrm{Cf}>6$. This is not unconnected to various metals and metallic compounds released from anthropogenic activities that add up to their natural background values. Chromium shows a non significant negative correlation with most of the trace metals at $p>0.5$ this further confirm its high contamination ratio (table 4) and distinct anthropogenic source from other trace metals. The correlation coefficient matrix relationship of other trace metals; $\mathrm{Mn}, \mathrm{Ni}, \mathrm{Pb}$ affirmed a common anthropogenic source.

$\mathrm{Cr}$ contamination is majorly associated with effluents from leather and textiles productions [22] while, $\mathrm{Ni}$ and $\mathrm{Pb}$ have been reported to be associated with effluents from electroplating, batteries storage, land disposals, sewage sludge, paint and dyes, effluents from crude oil transportations, fertilizers and vehicular emissions [22,4]. These effluents are traceable to solid wastes, allochtonous deposits and marine debris such as high and low density polythene, empty cans of food/pesticide sprays, glass bottles, used car tyres, worn clothes and a host of others that moved alongside sea hyacinth in the NIOMR Jetty point. These features were highly conspicuous in early October (plate1). Marine debris has contributed to the high level of pollutants found virtually around the harbour and this is in agreement with past researchers [7, 23]. However, most of these wastes are non-biodegradable and continuously leach heavy metals into the water body [9].

Judging from the monthly variation in the trace metal concentration, there is an observed higher concentration in $\mathrm{Cr}$, $\mathrm{Mn}$ and $\mathrm{Pb}$ in October. The high trace metal concentration in the month is attributed to reduced rain events (towards the end of wet season) and increased fresh water incursions from adjourning creeks and Badagry Lagoon; this is in agreement with the assertion by past researchers [24, 25]. The dilution from floodwater and the introduction of allochtonous material prevalent in October and high rate of tidal fluctuations(sea/fresh water incursion) which has been reported to have a tremendous influence on the coastal waters of the Lagos harbour (experienced in late September-early October) may not be unconnected to the high concentrations of $\mathrm{Cr}, \mathrm{Pb}$ and $\mathrm{Mn}$. This is also in agreement with the work of past researchers [26;27-29] that affirmed that the dilution and enriching effects of floodwater governs the biota distribution of the Lagos harbour.

The overall degree of contamination and the pollution 
index ratio trends are: medium depth profile (2.6meters) $>$ bottom depth profile (5.2meters) $>$ surface depth profile (0.2meters) fig 7 and 8 . The highest contamination factor at the 2.6 meters depth is in agreement with the earlier proposed dilution factor which led to the introduction of allochtonous materials into the water body.

The low abundance of $\mathrm{Cu}$ and $\mathrm{Zn}$ may be as a result of uptake, and their low pollution index tends to relate them to background values (fig 8).However, Zinc shows a nonsignificant positive correlation with $\mathrm{Mn}$ (very high $\mathrm{CF}$ values), this factor can be reliably linked to a dilution in the background concentration of zinc metal. This same factor can be adduced for Copper (low CF) which exhibit a strong correlation with $\mathrm{Pb}$ (very high $\mathrm{CF}$ ).

The percentage contributions of the toxic metals $(\mathrm{Cr}, \mathrm{Mn}$, $\mathrm{Pb}$ and $\mathrm{Ni}$ ) to pollution index are shown in fig 9, 10 and 11.The peak percentage contributions of $\mathrm{Cr}(42 \%)$ at the 0.2 meters profile, $\mathrm{Pb}(39 \%)$ at 2.6 meters and $\mathrm{Cr}(48 \%)$ at 5.2 meters is in agreement with the calculated pollution index ratios (PI), degree of contamination (DC) and the descending order of the trace metal concentration in the NIOMR Jetty (see table 1\&2).

Iron, copper and Zinc were not used in the contamination degree and pollution index calculations based on relatively high natural concentrations of Fe metal in marine water and sediments; it is not expected to be substantially enriched from anthropogenic sources [30] and the low CF values of the latter.

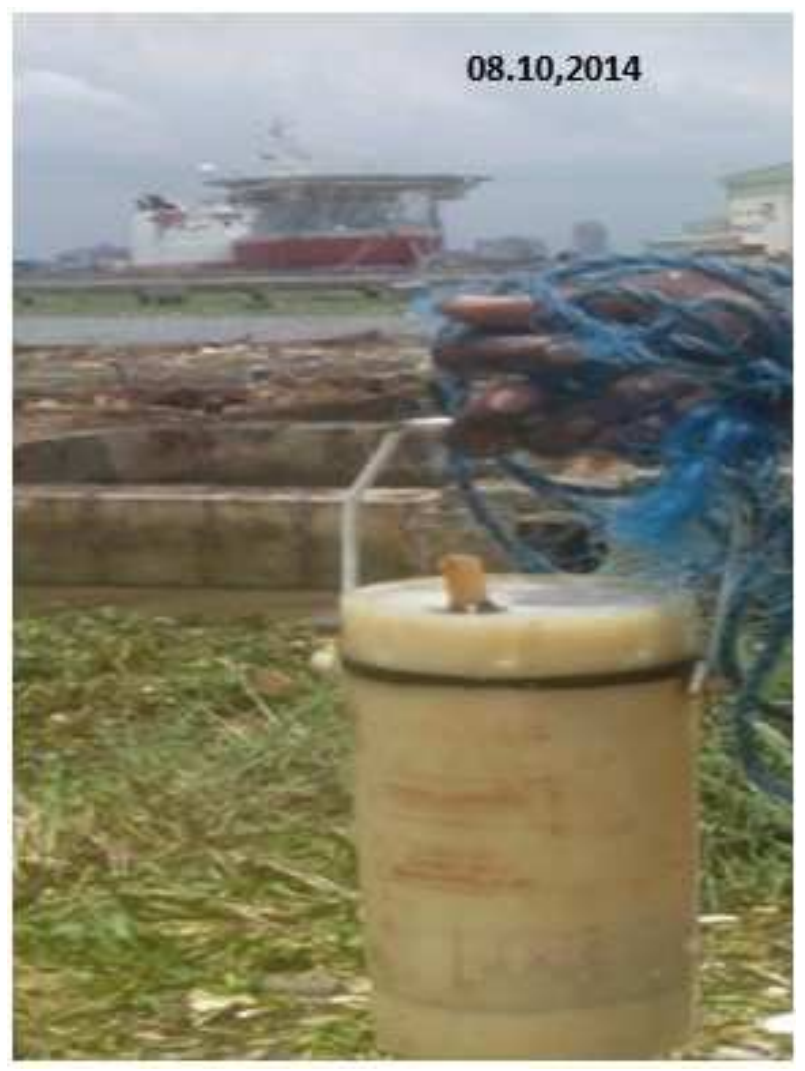

Plate 1. Showing water sampler and marine debris flowing alongside water hyacinth at the NIOMR Jetty.

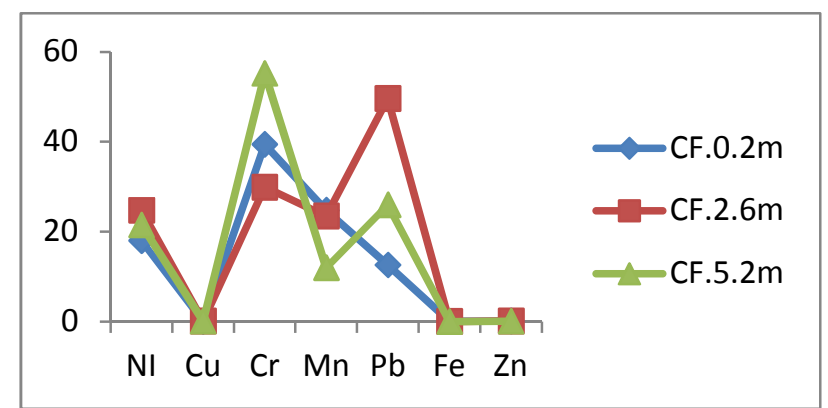

Fig. 6. The plots of contamination factor of trace metals with depth Cfcontamination factor, m-meter.

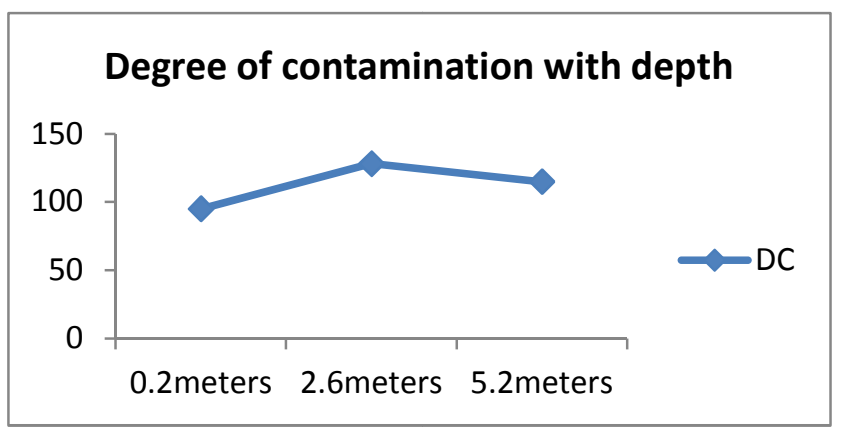

Fig. 7. Showing the degree of contamination of the NIOMR Jetty point with depth DC-Degree of contamination.

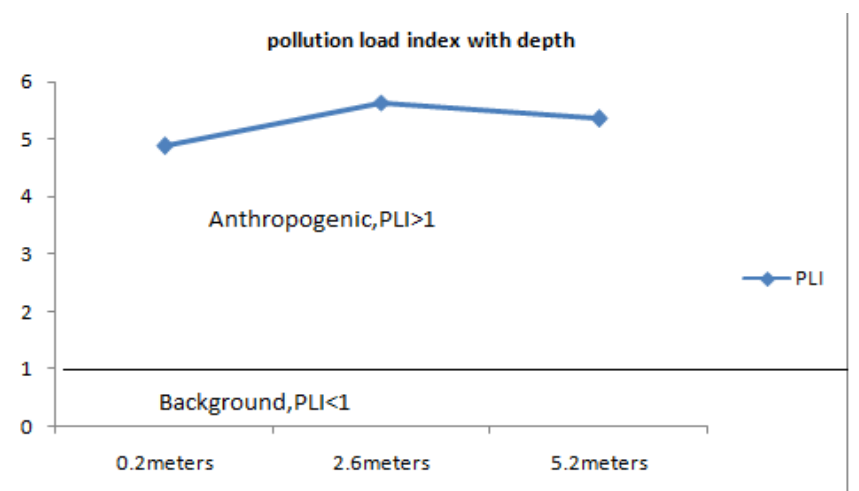

Fig. 8. Showing the pollution index of the NIOMR Jetty point with depth PLI-Pollution load index.

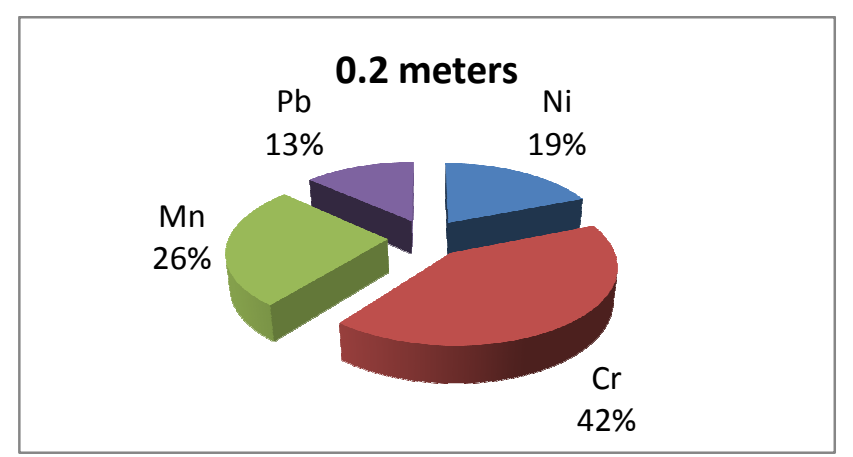

Fig. 9. Percentage of toxic metal contributions to the pollution index in the surface depth (0.2meters) at the NIOMR Jetty. 


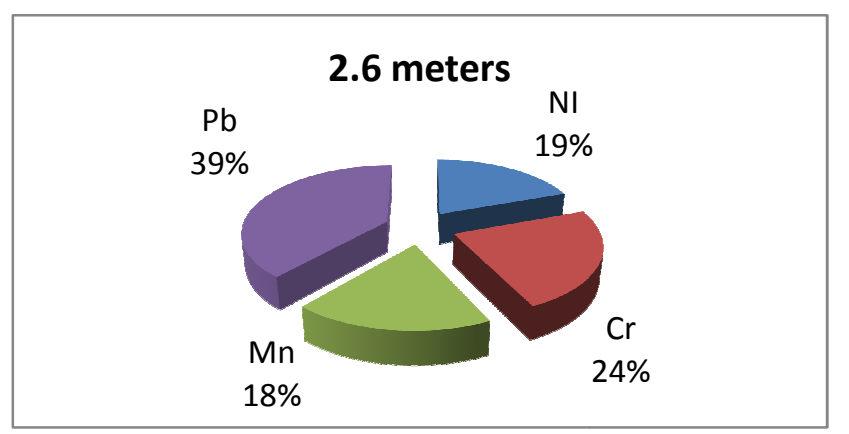

Fig. 10. Percentage of toxic metal contributions to the pollution index at the depth (2.6meters) at the NIOMR Jetty.

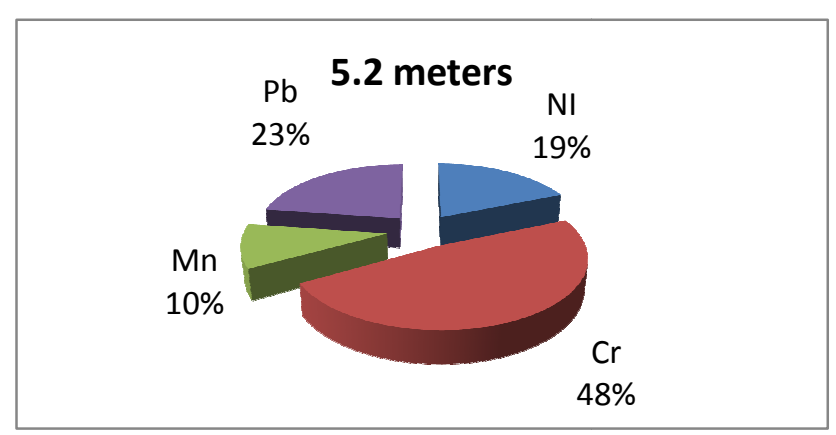

Fig. 11. Percentage of toxic metal contributions to the pollution index at (5.2meters) in the NIOMR Jetty.

\section{Conclusion}

The depth profiling sampling exercise in the NIOMR Jetty point has partially exposed the contamination pathways of trace metals around the Lagos Harbour. Copper and zinc in the NIOMR Jetty point fall below the anthropogenic enriched metals, and tend to be naturally derived, while $\mathrm{Pb}, \mathrm{Cr}, \mathrm{Mn}$ and Ni metals fall within the high contamination index ratio, hence, shows the dominance of anthropogenic enrichment. The contamination degree and the pollution index which signifies the overall contamination and toxicity rate of these trace metals also indicate progressive contamination in the NIOMR Jetty point. Low trace metal concentrations are not necessarily "natural" just because the levels are indeed low (Low trace metal concentrations may represent a mixture of small quantity of pollutants diluted by a large amount of natural water with a low trace metal content) and elevated concentrations of metals do not necessarily pose a threat as they may not be available for excessive aquatic organism's uptake. Therefore, contamination index determination is a very useful tool in the trace metal evaluation rather than the sole dependence on its high/low concentration above the permissible level.

Fresh/seawater incursions, anthropogenic effluents, precipitations, allochtonous deposit from marine debris, tidal fluctuations and mixing (ocean surge) are among the factors that control the concentrations and cycling of trace metals around the Habour. The highest contamination of toxic metals at the medium depth profile ( 2.6 meters) asserted the dominance of mixing and dilution in the NIOMR Jetty.

A strong regulation in the anthropogenic activities (indiscriminate dumping of sewage and domestic waste) in the Lagos Lagoon axis is highly essential. Though dredging is inevitable to maintain sufficient water depth in shipping channels and harbors, which are continually filled in by deposition.

This project is in progress and will be beneficial if it's extended to other Lagoons, adjourning creeks and Nigerian continental waters so as to further expose the vertical distributions and natural/anthropogenic pathways of trace elements in these axes.

\section{Acknowledgement}

The author acknowledge the Head of department, Physical and Chemical oceanographic section of the Nigerian Institute for oceanography and marine research, Victoria Island, Lagos, Nigeria, Dr Unyimadu John Paul, for his innovations, quality guidance and assistance in the course of doing this project.

\section{References}

[1] Turner, A. (1996), Trace metals portioning in estuaries importance of salinity and particulate concentration. Marine Chemistry, 54, pp27-39.

[2] Okoye, C.O,. Onwuka,S.U. and Obiakor, M.O.(2011). Pollution studies in Lagos and its environmental consequences. A review. Tropical built environment journal. 1(1) pp42-57.

[3] Amaeze, N.H. (2009). Comparative account of the Microfauna and Planktonic Communities of two polluted creeks associated with the Lagos Lagoon System. MSc. Thesis, University of Lagos, 2009.

[4] Popoola, S.O,.Hauwa, M,.Oyeleke P.O.and Odeyemi,O.E.(2014).The effect of Ambient particulate metal concentrates in Lagos metropolis and the adjoining water bodies, Northwest f Lagos Lagoon. Scientific Research Journal (SCIRJ) vol(11), pp29-57.

[5] Olatunji, A. S. and Abimbola, A.F.(2010).Geochemical Evaluation of the Lagos Lagoon Sediments.World Applied Sciences Journal 9 (2): 178-193.

[6] Balogun, K. J., Ladigbolu, I.A. and Olajire, E.D. (2011).Hydrochemistry of a Tropical harbor: Influence of Industrial and Municipal inputs. Journal of Appl. Science and Environmental management, Vol. 15 (4) pp 575- 581.

[7] Ajao, E. A.(1996) .Review of the state of pollution of the Lagos Lagoon. NIOMR Tech. Paper No. 106.

[8] Onyeama, I. C. and Popoola, R.C.(2013). The physicochemical characteristics, chlorophyll a levels and phytoplankton dynamics of the east mole area of the Lagos harbor Lagos. Journal of Asian Scientific Research, 3(10) pp 995-1010.http://aessweb.com/journal-detail.php?Id=5003.

[9] Nubi,O.A., Ajao,E.A.and NubiA.T. (2008). Pollution assessment of the impact of coastal activities on Lagos Lagoon, Nigeria Science World Journal, vol. 3(2), pp. 83-88.

[10] Nubi,O.A., Oyediran, L.T. and Nubi, A.T. (2011).Inter-annual trends of heavy metals in marine resources. African Journal of Environmental Science and Technology Vol. 5(2), pp. 104-110 
[11] Omatshola, M.E. and Adegoke, O.S.( 1981). The tectonic evolution and Cretaceous a stratigraphy of the Dahomey Basin. J. Mining and Geol., 54: 65-87.

[12] Balogun,K.J. and Ladigbolu, I. A. (2011). Nutrients and Phytoplankton Production Dynamics of a Tropical Harbor in Relation to Water Quality Indices ; journal of America science 6(9) 2010 pp. $261-275$.

[13] Balogun, K.J., Adedeji,A.k. andLadigbolu,I.A.(2014). Primary production estimation in the euphotic zone of a tropical harbor ecosystem, Nigeria. International Journal of Scientific and Research Publications, Volume 4, Issue 8, August 20141 ISSN 2250-3153.

[14] APHA. (1998). Standard method for the examination of water and waste water. 20th Edn., New York: American Public and Health Association.

[15] Nishida,H., Miyai,M,.Tada,F. and Suzuki S.(1982) .Computation of the Index of Pollution Caused by Heavy Metals in River sediment, Environmental Pollution Series B, Chemical and Physical, Elsevier, Vol. 4, No. 4, 1982, pp. 241- 248. http://dx.doi.org/10.1016/0143-148X (82)90010-6

[16] Hakanson, L.(1980). An ecological risk index for aquatic pollution control a sediment logical approach. Water Res.14, (2), pp 975.

[17] Lee, J.S,. Chon, H.T,. Kim, J.S,. Kim, K.W. and Moon, H.S.(1998) .Enrichment of Potentially Toxic Elements in Areas Underlain by Black Shales and Slates in Korea," Environmental Geochemistry and Health, Vol. 20, No. 30, pp. 135-147.

[18] World Health Organisation, (1993). Revision of WHO Guidelines for Water Quality. WHO Geneva.

[19] Taylor, S.R. and McLennan, S.M. (1995). The geochemical evolution of the continental crust. Reviews of Geophysics, 33, pp241-265.

[20] Tomlinson, D.L,. Wilson, J.G., Harris, C.R. and Jeffney,D.W. (1980). Problems in the assessment of heavy metals levels in estuaries and the formation of pollution index. Helgol. Wiss. Meeresunters, pp33, 566.
[21] Davis, J.C. (1986).Statistics and Analysis in Geology. John Wiley and Sons, New York, 64pp.

[22] Dara, S.S. and Srivastava R. (2009). Energy environment ethics and society. Revised edition, S.Chand\& company limited, Ramnagar, New Delhi, 426p.

[23] Onyema, I.C.(2013). The Physico-Chemical Characteristics and Phytoplankton of the Onijedi Lagoon, Lagos. Nature and Science, 11(1) pp 127-135.

[24] Onyema, I.C. (2010). Phytoplankton diversity and succession in the Iyagbe lagoon, Lagos. European Journal of Scientific Research, 43(1), pp61-74.

[25] Onyema, I.C. (2011). The Water Chemistry and Periphytic Algae at a Cage culture Site in a Tropical Open Lagoon in Lagos. actaSATECH, 4(1): 53-63.

[26] Brown, A.C. and. Oyenekan,J.A(1998). Temporal variability in the structure of benthic macro-fauna communities of the Lagos lagoon and harbour, Nigeria. Pol Arch Hydrobiol, 45: 45-54.

[27] Chukwu, L. O. and Nwankwo, D. I. (2004). The impact of land based pollution on the hydro-chemistry and macro benthic community of a tropical West African Creek from the Nigerian territorial waters. The Ekologia.(2): pp19. African Journal of Environmental Science and Technology Vol. 5(2), pp. 104-110.

[28] Onyema, I.C. (2008). Phytoplankton biomass and diversity at the Iyagbe lagoon Lagos, Nigeria. University of Lagos, Akoka. Department of Marine Sciences.

[29] Onyema, I.C,.Nwankwo, D.I. and Owolabi, K.O.(2008). Temporal and spatial changes in the phytoplankton dynamics at the tarkwa-bay jetty in relation to environmental characteristics. Journal of Ecology Environment and Conservation, 14(4): pp1-9.

[30] Niencheski, L.F., Windom, H.L. and Smith, R. (1994). Distributions of particulate trace metal in Patos Lagoon Estuary (Brazil). Marine Pollution Bulletin, 28, pp96-102. 